\title{
Applying behavioural science to refugee integration
}

Sanders, J.G. ${ }^{1,2,{ }^{*}}$, Castle, E. ${ }^{3}$, Tan, K. ${ }^{4}$, and Jenkins, R. ${ }^{1}$

1 Department of Psychology, University of York, York, UK

2 Department of Psychological and Behavioural Science, London School of Economics and Political Science, London, UK

3 Department of Education's Behavioural Insights Unit, London, UK

4 International Rescue Committee's Airbel Center, New York, USA

*Corresponding Author: Jet G. Sanders, Department of Psychological and Behavioural Science, London School of Economics and Political Science, London, UK, j.g.sanders@Ise.ac.uk 


\section{Abstract}

Successful refugee and migrant integration has been shown to generate novel opportunities for development, and to enrich countries economically, socially and culturally. Nonetheless integration is one of the most complex issues of our time. Here we review this problem from a behavioural science perspective. Behavioural science brings together insights from psychology, behavioural economics, neuroscience, and sociology to devise and improve population-level interventions and to develop more effective policies. One approach in behavioural science is commonly referred to as 'nudging'. Recently there has been a growing interest in nudge strategies among both practitioners and academics, in part because the strategies are cheap to implement. Here we provide an overview of such strategies and their applicability to refugee integration. By addressing two sectors of society where behavioural science is currently being applied (education and employment), we examine how behavioural evidence may be used to bypass barriers and facilitate drivers of integration. Our review (i) reveals that few interventions aimed at refugee integration use a behavioural science approach, (ii) highlights areas in which this approach could be especially effective, and (iii) identifies some behavioural science techniques that may be counterproductive.

\section{Introduction}

Behavioural science aims to explain decision-making above and beyond what standard economic theory would predict, by integrating knowledge from psychology, behavioural economics, neuroscience, and social sciences. In this chapter, we examine the application of this approach to refugee integration. Some work in this area pertains to migrants, refugees, or asylum seekers specifically. Other work combines two or more of these groups, depending on its purpose and scope. Although we draw on a range of sources, our main interest is how behavioural science informs refugee integration in particular. 
Integration efforts are most effective when they engage both host and refugee populations. Standard cost-benefit analysis would predict that both populations benefit economically in the long-term (Karakas, 2015; European Commission, 2016). For the host population, the refugee influx could lead to economic growth by addressing aging demographic trends, to take an example from the EU. Refugees may also improve the ratio of active workers (European Commission, 2016) and increase diversity, which has been shown to contribute to innovation, entrepreneurship and GDP growth (Karakas, 2015). For the refugee population, integration, in the long term, can benefit economic welfare, freedom, educational, and health outcomes (De Haas, 2005).

According to standard economic theory, people should act to secure these long-term benefits. Instead integration is often resisted, in part because both host and refugee populations are focused on short-term priorities such as first aid, shelter, and food, while postponing the provision and take up of education or mental and primary health care (Fratzscher \& Junker, 2015; UNHCR, 1997).

The tension between short-term and long-term thinking is core to one of the fundamental theories in behavioural science, the Dual System Theory (Kahneman \& Egan, 2011). This theory proposes that mental processing takes place on an fast, automatic, and intuitive level (System 1), as well as a slow, controlled, and reflective level (System 2). To optimise resource allocation, people operate in a System 1 state as much as possible. In the context of refugee integration, the proposal is that shortterm approaches and attitudes are likely grounded in System 1 thinking. In contrast, long-term benefits are captured by System 2 thinking. This distinction applies to thinking in both host and refugee populations.

Dual System Theory offers a behavioural perspective on what may limit progress towards effective integration. Historically, the dominant strategy has been to engage host and migrant populations in their System 2 state, with information being provided to illustrate the long-term benefits of integration (e.g. the European Commission's Refugee Awareness Project). Relaying such information is clearly important, but extensive research has shown that requiring people to function and make decisions in a reflective state is an unscalable, costly, and slow path to 
achieving behaviour change (see systematic review by Webb \& Sheeran, 2006). For example, knowing which food is healthy does not guarantee healthy food choices (e.g. Johnson et al., 2012).

In contrast, behavioural science strategies organise the environment so that the desired behavioural outcomes are as closely aligned as possible with System 1, sometimes bypassing System 2 altogether. This approach is also known as choice architecture (Johnson et al., 2012). A classic instantiation of choice architecture is the switch from a self-enrolment ('opt-in') to auto-enrolment ('opt out'), in line with the desired outcome. For example, Madrian and Shea (2001) showed that most people want to save for a pension and know that it is important. Yet out of inertia, many do not save. Changing the opt-in system to an opt-out system increased the proportion of workers saving toward a pension from $49 \%$ to $86 \%$. To take another example, recent work suggests that merely changing the timing of a decision can affect the outcome (Artavia-Mora, Bedi, \& Rieger, 2017; Ellis \& Jenkins, 2012; Sanders \& Jenkins, 2016).

A first step towards refugee integration is to identify System 1 biases and heuristics that affect host and refugee populations. Often, these will be situation dependent. However, we can begin by identifying some general ways in which a refugee population may differ from other populations.

Refugees generally face greater uncertainty than local citizens (Aspinall \& Watters, 2010). The particular circumstances leading to relocation vary greatly (Hagen-Zanker, 2008), as do circumstances of arrival. But common to many refugees is the prospect of 'starting again' (Agier, 2008). Human capacity to envision a new start is rooted in experiences of the past or present (Bar, 2011). Within displaced populations, the emerging situation may depart from previous experience in many ways (e.g. Berry, 1997). For example, it may require understanding the local rental market, enrolling a child in school, or taking the subway. All of these tasks require extensive System 2 engagement (deliberative thinking), increasing cognitive load (Sweller, 1988; Sweller, Van Merrienboer \& Paas, 1998). With System 2 occupied by everyday tasks, it falls to System 1 to handle effective integration. 
In addition, many refugees and migrants must contend with a state of scarcity. Scarcity describes the condition of having insufficient resources to cope with demands (Lynn, 1991). Many refugees arrive in a state of material scarcity, having travelled with minimal resources, often to countries where there are insufficient state provisions to accommodate the influx of people (Ratha et al., 2011; UNHCR, 2016). One insidious side effect of material scarcity is that it can lead to cognitive scarcity, entrenching the original position. Material scarcity tends to focus System 2 resources on immediate problems (Karau \& Kelly, 1992). The resulting 'tunnel vision' can lead to desirable consequences for the problem at hand. However, it can also lead to undesirable consequences in the form of myopic or impulsive behaviour, with shortterm gains being prioritised over long-term gains. In a laboratory demonstration of this effect, Tomm \& Zhao (2016) allocated participants to a poor condition (\$20 budget) or a rich condition ( $\$ 100$ budget) before presenting a restaurant menu. While poor participants spent more time than rich participants looking at prices, they spent less time looking at an $18 \%$ discount on the bottom of the menu. Scarcity can induce neglect of non-focal information in the environment that could mitigate the scarcity itself. In the context of refugee integration, this might translate into financial worries obscuring job opportunities that could alleviate poverty. Thus, scarcity means not only a shortage of physical resources such as time and money, but also a shortage of cognitive resources such as attention and executive control.

The combination of uncertainty and scarcity is likely to leave refugees especially prone to System 1 thinking. The upside is that this provides an opening for System 1-focused behavioural interventions.

\section{Using behaviour change tools}

Various behaviour change tools are available for developing behavioural interventions. The design process generally starts by mapping the current pathway towards the desired outcome-in this case, refugee integration. As integration is a highly complex issue, it is usually measured indirectly via behavioural proxies such as language acquisition, family self-sufficiency or employment, enrolment in 
education, and housing permanence, depending on the measurement tool that is used (see Sturm, 2016 for an overview of tools).

In the early stages of planning an intervention, a behavioural analysis may be used to map the physical routes (e.g. schools/community centres), barriers (e.g. time), and drivers (e.g. finding work) of optimal engagement with these behaviours. The analysis stage is often guided by a theoretical framework such as the Theoretical Domains Framework (TDF; Cane, O'Connor \& Michie, 2012) or the COM-B model and Behaviour Change Wheel (BCW; Michie, Stralen \& West, 2011). The TDF allows practitioners to think through a pathway systematically, and to catalogue influences on the behaviours of interest. For example, French et al (2012) propose a four-step approach based around the following questions: Who needs to do what, differently? Using a theoretical framework, which barriers and enablers need to be addressed? Which intervention components (behaviour change techniques and modes of delivery) could overcome the modifiable barriers and enhance the enablers? And how can behaviour change be measured and understood?

COM-B and the BCW are used to identify drivers for those behaviours that may be most amenable to change. Ideally, this process can identify a series of new intervention opportunities that foster migrant integration for an entire system. For example, the behavioural analyses of antimicrobial resistance (Pinder et al., 2015) and climate change (Hallin et al., 2017) both address problems on a global scale.

Once opportunities for behavioural intervention have been identified, the next step is to supplement, tweak, or restructure the existing pathway in service of the desired outcome. The traditional approach might involve launching an information campaign or a costly training programme. In contrast, a core principle of the behavioural science approach is that a small change, such as changing the default option or simplifying an information letter, can yield disproportionate benefits. This allows interventions to be low cost, and scalable to entire target populations if shown to be effective. Changing the default option is a prime example of a behavioural intervention that balances the level of intervention and the freedom of the individual. The Nuffield Ladder of Intervention (Nuffield Council on Bioethics, 2015) 
characterises this balance by introducing various intervention options, from 'doing nothing' - where no state intervention occurs, to 'eliminating choice' - where the state removes the choice from the individual entirely. Table 1 illustrates this range of options for the case of smoking reduction.

\section{RUNG OF LADDER}

\section{Eliminate choice}

Restrict choice

Guide by disincentives

Guide choice by incentives

Guide choice by changing the default policy

Enable choice

Provide information

Do nothing

\section{EXAMPLE}

No smoking for minors

No smoking in workplaces

Taxes on cigarettes

Stop smoking during pregnancy

Plain packaging requirements

Free 'stop-smoking' program enrolment

Website, leaflets and adverts

Table 1: Nuffield ladder of intervention, applying different levels of intervention to smoking reduction.

One concern about stronger interventions (eliminating or restricting choice) is that individuals may feel that their freedom to choose is curtailed, causing upset and resistance if changes are not managed carefully. The complementary concern about minimal intervention is that it doesn't guide the population towards the collectively beneficial choice. The middle strategies are frequently considered forms of nudging, "ways of influencing choice without limiting the choice set or making alternatives appreciably more costly in terms of time, trouble, social sanctions, and so forth" Hausman \& Welsh (2010). Ideally, nudge strategies can be used to direct the population towards the collectively desirable option of refugee integration, without limiting individual choice and without placing unrealistic expectations on individual responsibility.

The potential of nudge to promote behaviour change across public domains for social good was popularised by Sunstein and Thaler (2008). Not long after, the British government created a 'Nudge Unit', the Behavioural Insights Team (BIT, 2014), which initially focused on matters such as improving tax returns and increasing rates of organ donation (BIT, 2014). Along with a number of trials that indicated strong potential for the approach, BIT devised several influential frameworks. First, BIT advocated that behavioural science in the public sphere 
should use randomised control trials (RCTs) to check for efficacy and to ensure that interventions have no adverse effects (see Test, Learn, Adapt framework by Haynes et al., 2012). Second, they developed two frameworks to make behavioural science methods more accessible to policy makers and practitioners. In 2010, the MINDSPACE framework (Dolan et al., 2010) was introduced, capturing 9 of the most effective behavioural insights techniques in mnemonic form to ease engagement (see Table 2, Dolan et al., 2010; Dolan et al., 2012).

\section{MINDSPACE CUE}

Messenger

Incentives

Norms

Defaults

Salience

Priming

Affect

Commitments

Ego

\section{BEHAVIOUR}

We are heavily influenced by who communicates information to us Our responses to incentives are shaped by predictable mental shortcuts We are strongly influenced by what others do We 'go with the flow' of pre-set options

Our attention is drawn to what is novel and seems relevant to us Our acts are often influences by sub-conscious cues Our emotional associations can powerfully shape our actions We seek to be consistent with our public promises, and reciprocate acts We act in ways that make us feel better about ourselves

Table 2: The MINDSPACE framework for behaviour change. Nine behavioural techniques that could promote behaviour change. Image retrieved from Dolan et al., (2012).

Soon after, in 2014, the EAST framework was published. The EAST framework is less extensive than COM-B, BCW or MINDSPACE, but simpler to use. It proposes that interventions are more likely to be effective if they are Easy, Attractive, Social, and Timely (BIT, 2014; Table 3).

A decade on from Sunstein and Thaler (2008), teams of behavioural scientists are employed in nearly all British government departments, as well as the governments of over 30 other countries, global organisations such as the UN and World Bank, and a range of international charities and specialist consultancies (Sunstein, Reisch \& Rauber, 2018). This global reach is matched by the range of projects in which behavioural science principles are applied, including global health pandemics such as obesity and air pollution, environmental issues such as climate change, and social issues such global poverty, gender inequality, tax evasion, violent crime, homelessness, and joblessness (Lourenço et al., 2016). 

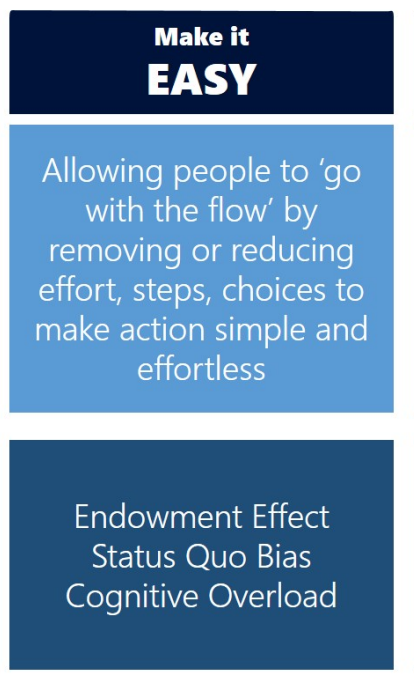

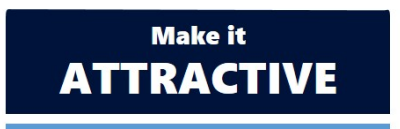

Presenting benefits in a

way that maximizes

perceived value. This

includes increasing the

salience of your offer

Availability Bias

Anchoring

Loss Aversion

Optimism Bias

Scarcity

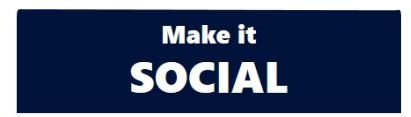

Harnessing social / peer

'pressure' by showing

desired behaviours are

supported by others in a

social group and

encouraging shared

commitments

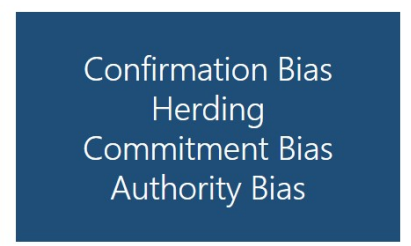

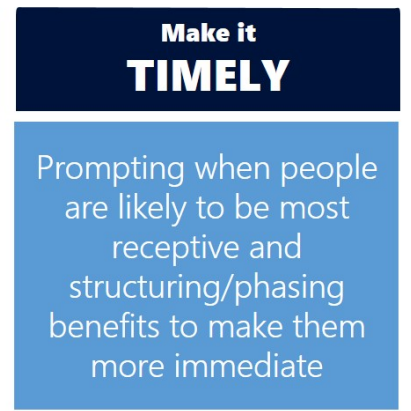

Present Bias

Hyperbolic Discounting

Duration Neglect

Hot/Cold States

Table 3: The EAST framework for behaviour change. Top row: Four behavioural principles, Middle row: principles that support these; Bottom row: evidenced biases and heuristics that can be used to activate these principles. Image retrieved from https://bit.ly/2KqIQa0

Whatever techniques are used, behavioural science interventions must be accompanied by rigorous assessment methods. It is essential to establish the effectiveness of an intervention before rolling it out (Haynes et al., 2012).

Randomised Control Trials (RCTs) have been recognised as the gold standard in testing medical interventions for over 60 years, partly because they allow researchers to dissociate treatment effects from changes over time. However, it is only recently that RCTs have entered mainstream social science and policy research. Slow adoption in this sector is partly due to the misapprehension that testing takes too much time and money (see Haynes et al., 2012 for a review), and partly due to a reliance on common sense as a means of divining what will work. However, RCTs have been shown to overturn even very long-standing assumptions. For example, Scared Straight was a US crime reduction programme introduced in the late 1970s, which aimed to deter high school students from a life of crime through interaction with prison inmates. Early studies concluded that the intervention was highly effective in reducing crime rates (see Finckenauer, 1982, for discussion), and similar programmes were trialled in at least six countries. It was only when an RCT was carried out, 25 years post-implementation, that the intervention was found to have increased crime rates all those years (Petrosino, Turpin-Petrosino \& Buehler, 2003). A background decrease in the crime rate over time had been wrongly 
attributed to the intervention. In a very different setting, the Behavioural Insights Team ran an RCT to test whether attendance at adult literacy classes could be improved by a financial incentive of $£ 5$ per session. Surprisingly, these payments actually reduced attendance relative to the control group - the very opposite of the expected effect (Brooks et al., 2008; see Festinger \& Carlsmith, 1959, for suppressive effects of reward). As these and many other examples illustrate, intuition is no substitute for evidence.

\section{Relevant examples of behavioural interventions}

Behavioural science interventions have been trialled by a number of global organisations, including United Nations and the World Bank (WB, 2018; UNDP, 2017; WB, 2016; WB, 2015). One particularly relevant initiative is a United Nations Development Programme intervention that aims to integrate Syrian refugees in Jordan via a skills exchange programme (UNDP, 2016). This particular intervention is ongoing, and the results have not yet been published. However, several interventions have been conducted in related areas. Here we describe two examples-one in employment and one in education. Each example aligns with behavioural principles and techniques described in the EAST and MINDSPACE frameworks.

\section{Employment}

Employment is one of the most important issues in refugee integration. Gainful employment can increase economic independence, foster interactions between refugees and host populations, strengthen language skills, and develop self-esteem and self-reliance (Ager and Strang, 2008). Here, we discuss two areas where behavioural science could be applied-employment rights and recruitment processes.

\section{Employment rights}


In the UK, individuals granted refugee status are permitted to work in any profession and at any skill level. Asylum seekers on the other hand, are not permitted to work. A critical problem faced by people in this situation is the time taken to grant refugee status. Hainmueller, Hangartner and Lawrence (2016) found a causal link between the length of time a refugee waits for a decision on their asylum claim and their subsequent economic integration. Each additional year of waiting from the moment of arrival reduced subsequent employment rates by 4 to 5 percentage points (16 to $23 \%$ below the average rate). Even a small reduction in the time taken to decide an asylum seeker's status could reduce public expenditure and increase the economic and social integration of the refugee population. Below we explore two possible solutions to this challenge.

Intervention 1: Reducing cognitive load through simplification. Simplification has been effectively used to encourage individuals to comply with a range of behaviours. In one study, simplifying letters from government departments resulted in a $5-10 \%$ increase in response rate by making the behavioural request clearer (BIT, 2014). Such interventions have typically targeted members of the public, for example, encouraging timely tax payments (BIT, 2014) or increasing uptake of the NHS Health Check (PHE, 2015). However, the same approach could be applied to government systems internally to streamline handling of asylum claims. If simplification improves communication, there is no reason why intra-government communication should be excluded.

Intervention 2: Changing the default. An example of a stronger nudge would be to change the default. A natural experiment in Germany provides empirical evidence for the impact of changing the default for asylum seekers and employment restrictions. In 2000, a court ruling prompted a reduction in the length of time asylum seekers must wait before seeking employment. Those arriving in Germany before 2000 , on average, waited about 19 months before they were permitted to seek employment. Individuals arriving after 2000, had to wait 12 months. Marbach, Hainmueller and Hangartner (2017) found that employment rates were about 20 percentage points lower for those refugees who had to wait longer before entering the labour market. The employment gap between these groups persisted for ten years after the waiting period was reduced. 


\section{Recruitment processes}

Refugees and asylum seekers often face multiple layers of discrimination. Unsurprisingly, forced migration can lead people to fall behind in education or work experience or both (WHO, 2018). Racial discrimination may compound this disadvantage. Moreover, more than 80 per cent of the world's refugees are women and their dependent children, who tend to be victim to racial and gender discrimination (Pittaway \& Bartolomei, 2001). Most workplaces do not actively discriminate, but may harbour unconscious bias (Cortina, 2008). Unconscious bias refers to automatic favouritism influenced by our background, cultural environment and personal experiences, expressed through quick judgments and assessments of people and situations. There are a number of approaches to overcoming unconscious bias in the workplace. Here we outline two that are relevant to employment of refugees and migrants.

Intervention 1: Anonymous or blind applications. A review of the experimental evidence of the impact of anonymised job applications finds that anonymous hiring can reduce discrimination, but only if discrimination was in fact present (Krause, Rinne and Zimmermann, 2012). Anonymous hiring may have no effect if discrimination does not exist initially, as it can also prevent employers from applying measures such as affirmative action in the first stages of the recruitment process (White, 2003). Specific to refugee and migrant populations, applications may be interpreted more positively if the identity of the candidate is available. For example, if recruiters are aware of an applicant's migration background, they may be better placed to understand the applicant's labour market experience or language skills. The use of anonymous job applications, therefore, crucially depends on the initial context of individual organisations.

Intervention 2: Priming values. A UK police force identified a test in their application process that appeared to disadvantage minority applicants. With a view to increasing diversity, they redesigned the wording that introduced the test. Specifically, they added the instruction, "Before you start the test, I'd like you to take 
some time to think about why you want to be a police constable. For example, what is it about being a police constable that means the most to you and your community?". This new instruction primed applicants to reflect on their values and their contribution by representing the social identity of their community within the police force. The results showed a $50 \%$ increase in the probability of passing the test for minority applicants in the treatment group, with no effect on other applicants. This simple intervention closed the racial gap in the pass rate without lowering the recruitment standard or changing the assessment questions (Linos, Reinhard and Ruda, 2017).

\section{Education}

The educational needs of refugees are highly varied. Some may arrive with very little prior education. Others may be may be highly qualified, but find that their qualifications are not recognised. While the specific needs of individuals will be very different, two general behaviours appear to promote refugee integration-integration into mainstream formal education systems, and engagement in English for Speakers of Other Languages (ESOL) classes.

\section{Integration into mainstream formal education}

Quick access to quality education can equip refugees with the skills they need to succeed. Education is also an important channel for communicating the values of the host country, and supporting engagement with civic life. In short, education is central to successful integration (Bodwig, 2015). However, refugees may find themselves facing education systems that are complex and unfamiliar. Uncertainties surrounding eligibility for services and how to engage with those services can become a significant barrier to effective integration. Evidence from service uptake in related areas suggests that simplifying enrolment procedures and providing enrolment support can overcome this barrier.

Bettinger et al. (2009) examined low uptake of financial aid for college enrolment in low- and middle-income families. Those who received professional help with the application form were significantly more likely to submit an application, and were 8 per cent more likely to enrol in college. However, the simplified form alone did 
not produce a significant effect (Bettinger et al., 2009). This research indicates that individuals, including refugees, may need support that goes beyond classic nudges (such as simplifying procedural documents). Extrapolating from this research, providing assistance to refugees in engaging with unfamiliar educational systems could be an effective and efficient approach to integrating people into mainstream formal education. Support for refugees would require broad knowledge of (i) educational provision from early years to adult learning, and (ii) eligibility criteria for access to these opportunities.

\section{Learning the language of the host country}

Learning the language of the host country is one of the most important behaviours for refugees to pursue (British Council, 2016). It is considered a facilitator of refugee integration in nearly all measurement tools (Sturm, 2016). Learning the host language increases refugees' ability to engage successfully with public services, leading to a range of benefits including better health and wellbeing, education and employment, and social and civic integration (Casey Review, 2016). All of these benefits rely on adequate funding for language course. In addition, behavioural science also highlights a non-structural barrier to engagement with language learning. Time discounting refers to the relative value an individual places on a given outcome at different points in time (Frederick, Loewenstein and O'Donoghue, 2002). In general, immediate rewards are weighted more heavily than future rewards, and our preferences are often inconsistent over time (Laibson, 1997). Educational decisions illustrate the tension between short- and long-term benefits. Short-term investment of time, money, and cognitive resource is required to secure longer-term, uncertain payoffs such as more highly paid employment (Cawley \& Ruhm, 2011). An important consequence of time-inconsistent preferences is that individuals may spend resources in the present that their future self would prefer to have conserved, despite knowing the same information.

Refugees face many competing demands on their resources. Despite the larger longer-term payoffs of language learning, immediate pressures may lead refugees to pursue behaviours with smaller short-term payoffs. For example, a highly qualified refugee may take up unskilled labour to achieve stability in the near term (Atwell et 
al, 2009). Although there is little evidence this is based on the refugee population specifically, behavioural approaches to increasing engagement with adult learning provide some insight. Of particular interest are interventions that exploit social drivers of behaviour. Below we provide two examples.

Intervention 1: Study supporters. Hume et al. (2018) asked learners to nominate a 'study supporter' (e.g. a parent, sibling, mentor or friend) who would receive regular updates about the learner's studies via text. The update would encourage the supporter to engage the learner on study progress-for example, a recent topic, or revision for an upcoming test. This simple intervention increased attendance by $4.1 \%$ and attainment by $6 \%$, relative to a control group without study supporters.

Intervention 2: Buddy incentives. In a separate intervention, Hume et al. (2018) attempted to improve student attendance in Maths and English classes at Children's Centres by (i) providing a financial reward to parents if their children attended class, or (ii) randomly pairing each learner with another learner in the class. These intervention groups were compared to a control. Learners in each group received stamp card to monitor attendance. In the control and financial incentive group, these cards were used to monitor individual attendance. In the paired learner group, the card was shared between the two learners, and could only be stamped if both attended. Both interventions improved attendance compared to the control group. However, the buddy incentive, worked particularly well. Attendance increased from $43.6 \%$ to $75.3 \%$ in the buddy group.

These findings suggest that social incentives can be used to promote engagement in learning. In particular, a social incentive can provide an additional immediate reward to language learning and thereby motivate continued engagement. Potential interventions could include encouraging refugees to identify study supporters to discuss learning progress. Where social networks are not established, language learning providers could facilitate their creation by pairing each learner with a buddy. Where social networks are already in place,, language engagement could benefit from being funnelled through them. In this space too, community role models could exemplify continued engagement and help to bring 
new learners on board. Beyond language learning, we expect that social approaches could promote wellbeing and integration more broadly.

\section{Conclusion}

In this review we have offered a background and overview of behavioural science, outlined how behavioural science principles may apply to refugee and host populations, and suggested possible paths towards applying behavioural science to refugee integration globally. To illustrate how a behavioural science approach functions, we provided specific examples of government aligned interventions in education and employment, using principles described in the MINDSPACE and EAST frameworks. Although we confine ourselves to education and employment in this chapter, the same principles could be applied to other aspects of refugee integration, such as housing or health and wellbeing. A useful next step would be to carry out a behavioural analysis to determine where progress could be made most efficiently. Once intervention areas are identified, implementing changes can be quite simple, unlocking disproportionate progress towards successful integration and all the benefits that flow from it.

In all of these areas, it is essential that behavioural science interventions be tied to rigorous assessments. Randomised Control Trials (RCTs) have been widely adopted in the health sector as a means for evaluating medical interventions, and we suggest that behavioural science interventions should follow a similar path.

As a final point, we note that the use of nudge without consent has received widespread criticism from academics and members of the public. These criticisms tend not to concern a specific application (e.g. refugee integration), but rather the nature of the intervention itself. Much of the opposition stems from the ethical concern that nudging amounts to "manipulating people's choices" (Mitchell, 2004; Bovens, 2009). Indeed, Sunstein \& Thaler (2008) seem to subscribe to this view. A number of related criticisms have been advanced-that Libertarian Paternalism is an oxymoron (Mitchell, 2004), that nudge is merely paternalism in disguise (Vallgarda, 2012, Burgess, 2012; Furedi, 2011), and that nudging impairs autonomy (Furedi, 
2011; Bovens, 2009). Of course, nudge interventions are just one tool in the behavioural science toolkit. But given the high profile of such critiques, it is important to acknowledge that no truly neutral option exists. Consider a doctor discussing the risk of a treatment with a patient. The same information might be communicated in terms of a $90 \%$ survival rate or a $10 \%$ death rate, and these different framings will result in different rates of treatment uptake. Yet there is no way to abolish framing altogether. The doctor is obliged to pick something. This bind applies not only to word choice, but to countless other factors that influence each decision. To absorb this fact is to recognise that we are all nudgers and are always being nudged, whether we like it or not and regardless of anyone's intentions. Nudges are an inescapable feature of any decision-making context. The ethical question is not whether to nudge, but in which direction, and in whose interests.

\section{References}

Ager, A. \& Strang, A., (2008). Understanding integration: A conceptual framework. Journal of Refugee Studies, 21(2), 166-191.

Agier, M. (2008). On the margins of the world: the refugee experience today. Polity. Artavia-Mora, L., Bedi, A.S., \& Rieger, M. (2017). Intuitive help and punishment in the field. European Economic Review, 92, 133-145.

Aspinall, P. J., \& Watters, C. (2010). Refugees and asylum seekers: a review from an equality and human rights perspective. Research Report 52. Equality and Human Rights Commission.

Atwell, R., Gifford, S. M., \& McDonald-Wilmsen, B. (2009). Resettled refugee families and their children's futures: Coherence, hope and support. Journal of Comparative Family Studies, 677-697.

Bar, M. (Ed.). (2011). Predictions in the brain: Using our past to generate a future. Oxford University Press.

Behavioural Insights Team (2014) EAST: Four Simple Ways to Apply Behavioural Insights.

Berry, J. W. (1997). Immigration, acculturation, and adaptation. Applied Psychology, 46(1), 5-34. 
Bettinger et al. (2009), The Role of Simplification and Information in College Decisions: Results from the H\&R Block FAFSA Experiment, NBER Working Paper.

Bodwig. A., (2015) Education is the key to integrating refugees in Europe. Future Development Blog.

Bovens, L. (2009). The ethics of nudge. In Preference change (pp. 207-219). Springer, Dordrecht.

British Council (2016) Language for resilience: Supporting Syrian Refugees. Retrieved from_http://researchbriefings.files.parliament.uk/documents/CBP7905/CBP-7905.pdf

Brooks, G., Burton, M., Cole, P., Miles, J., Torgerson, C. \& Torgerson, D. (2008). Randomised controlled trial of incentives to improve attendance at adult literacy classes. Oxford Review of Education, 34(5), 493-504.

Burgess, A. (2012). 'Nudging' healthy lifestyles: The UK experiments with the behavioural alternative to regulation and the market. European Journal of Risk Regulation, 3(1), 3-16.

Cane, J., O'Connor, D., \& Michie, S. (2012). Validation of the theoretical domains framework for use in behaviour change and implementation research. Implementation Science, $7(1), 37$.

Cawley, J., \& Ruhm, C. J. (2011). The economics of risky health behaviors. In Handbook of Health Economics (Vol. 2, pp. 95-199). Elsevier.

Cortina, L. M. (2008). Unseen injustice: Incivility as modern discrimination in organizations. Academy of Management Review, 33(1), 55-75.

CRASH Trial Collaborators. (2005). Final results of MRC CRASH, a randomised placebo-controlled trial of intravenous corticosteroid in adults with head injuryoutcomes at 6 months. The Lancet, 365(9475), 1957-1959.

Dame Louise Casey, The Casey Review: A review into opportunity and integration, December 2016.

De Haas, H. (2005). International migration, remittances and development: myths and facts. Third World Quarterly, 26(8), 1269-1284.

Dolan, P., Hallsworth, M., Halpern, D., King, D., \& Vlaev, I. (2010). MINDSPACE: Influencing behaviour for public policy. 
Dolan, P., Hallsworth, M., Halpern, D., King, D., Metcalfe, R., \& Vlaev, I. (2012). Influencing behaviour: The mindspace way. Journal of Economic Psychology, 33(1), 264-277.

Ellis D.A., \& Jenkins, R. (2012) Weekday Affects Attendance Rate for Medical Appointments: Large-Scale Data Analysis and Implications. PLoS ONE 7(12): e51365. doi:10.1371/journal.pone.0051365.

Equality and Human Right Commission (2014). Employing Refugees: guidance for Employers

European Commision (2016) An Economic Take on the Refugee Crisis: A Macroeconomic Assessment for the EU. European Union, Institutional Paper 033

Festinger, L., \& Carlsmith, J.M. (1959). Cognitive consequences of forced compliance. Journal of Abnormal and Social Psychology, 58, 203-210.

Finckenauer J. O. (1982) Scared Straight and the Panacea Phenomenon. Englewood Cliffs, NJ: Prentice-Hall.

Fratzscher, M., \& Junker, S. (2015). Integrating refugees: A long-term, worthwhile investment. DIW Economic Bulletin, 5(45/46), 612-616.

Frederick, S., Loewenstein, G., \& O'Donoghue, T. (2002). Time discounting and time preference: A critical review. Journal of Economic Literature, 40(2), 351-401.

French, S. D., Green, S. E., O’Connor, D. A., McKenzie, J. E., Francis, J. J., Michie, S., Buchbinder, R., Schattner, P., Spike, N., \& Grimshaw, J. M. (2012).

Developing theory-informed behaviour change interventions to implement evidence into practice: a systematic approach using the Theoretical Domains Framework. Implementation Science, 7(1), 38.

Furedi, F. (2011). Defending moral autonomy against an army of nudgers. Spiked. [Online]. Retrieved on 05/09/2018.

Hagen-Zanker, J. (2008). Why do people migrate? A review of the theoretical literature.

Hainmueller, J., Hangartner, D. and Lawrence, D., (2016). When lives are put on hold: Lengthy asylum processes decrease employment among refugees. Science Advances, 2(8), p.e1600432. 
Hallin, S., Hooper, E. and Weyman-Jones, T. (2017) Case Study Evidence and Behavioural Analysis of Residential Energy Consumption in the UK. Open Journal of Energy Efficiency, 6, 14-40.

Hausmann D. and Welch B. (2010), Debate: To Nudge or Not to Nudge, Journal of Political Philosophy, 18, 123-136.

Haynes, L., Goldacre, B., \& Torgerson, D. (2012). Test, Learn, Adapt: Developing Public Policy with Randomised Controlled Trials. Cabinet Office.

Hume, S., O'Reilly, F., Groot B., Chande, R., Sanders, M., Hollingsworth, A., Ter Meer, J., Barnes, J., Booth, S., Kozman, E. and Soon, X. Z., (2018). Improving engagement and attainment in maths and English courses: insights from behavioural research. Department for Education. https://bit.ly/2ArEPAx Johnson, E. J., Shu, S. B., Dellaert, B. G., Fox, C., Goldstein, D. G., Häubl, G., Larrick, R.P., Payne, J.W., Peters, E., Schkade, D. \& Wansink, B. (2012). Beyond nudges: Tools of a choice architecture. Marketing Letters, 23(2), 487504.

Kahneman, D., \& Egan, P. (2011). Thinking, fast and slow. New York: Farrar, Straus and Giroux.

Karakas, C. (2015). Economic challenges and prospects of the refugee influx. European Parliamentary Research Service.

Karau, S. J., \& Kelly, J. R. (1992). The effects of time scarcity and time abundance on group performance quality and interaction process. Journal of Experimental Social Psychology, 28(6), 542-571.

Krause, A., Rinne, U., \& Zimmermann, K.F. (2012). Anonymous job applications in Europe. IZA Journal of European Labor Studies, 1(1), 5.

Laibson, D. (1997). Golden eggs and hyperbolic discounting. The Quarterly Journal of Economics, 112(2), 443-478.

Linos, E., Reinhard, J., \& Ruda, S. (2017). Levelling the playing field in police recruitment: Evidence from a field experiment on test performance. Public Administration, 95(4), 943-956.

Lourenço, J.S., Ciriolo, E., Almeida S.R., \& Troussard, X. (2016). Behavioural insights applied to policy. European Report 2016. EUR 27726 EN; doi:10.2760/903938

Lynn, M. (1991). Scarcity effects on value: A quantitative review of the commodity theory literature. Psychology \& Marketing, 8(1), 43-57. 
Madrian, B.C., \& Shea, D.F. (2001). The power of suggestion: Inertia in 401 (k) participation and savings behavior. The Quarterly Journal of Economics, 116(4), 1149-1187.

Marbach, M., Hainmueller, J., \& Hangartner, D. (2017). The Long-Term Impact of Employment Bans on the Economic Integration of Refugees. Science Advances, 4(9), eaap9519.

Michie, S., Van Stralen, M. M., \& West, R. (2011). The behaviour change wheel: a new method for characterising and designing behaviour change interventions. Implementation Science, 6(1), 42.

Mitchell, G. (2004). Libertarian paternalism is an oxymoron. Northwestern University Law Review, 99, 1245.

Nuffield Council on Bioethics. (2015) http://nuffieldbioethics.org/wpcontent/uploads/2014/07/Public-health-Chapter-3-Policy-process-andpractice.pdf (accessed Jun 2015)

Petrosino, A., Turpin-Petrosino, C., \& Buehler, J. (2003). Scared Straight and other juvenile awareness programs for preventing juvenile delinquency. Campbell Review Update I. The Campbell Collaboration Reviews of Intervention and Policy Evaluations (C2-RIPE). Philadelphia, Pennsylvania: Campbell Collaboration.

Pinder, R., Sallis, A., Berry, D., \& Chadborn, T. (2015). Behaviour change and antibiotic prescribing in healthcare settings. Literature review and behavioural analysis. Public Health England.

Pittaway, E., \& Bartolomei, L. (2001). Refugees, race, and gender: The multiple discrimination against refugee women. Refuge: Canada's Journal on Refugees, 19(6).

Public Health England (2015) Low cost ways to increase NHS Health Check attendance: results from a randomised controlled trial.

Ratha, D., Mohapatra, S., \& Scheja, E. (2011). Impact of migration on economic and social development: A review of evidence and emerging issues. The World Bank.

Sanders J.G., \& Jenkins, R. (2016) Weekly Fluctuations in Risk Tolerance and Voting Behaviour. PLoS ONE 11(7): e0159017. doi:10.1371/journal. pone.0159017. 
Sturm, D. (2016) Measuring Refugee Integration - The International Context, Research and Evaluation Manager, USCCB/MRS Oct. 21, 2016 (Draft) Retrieved from https://c.ymcdn.com/sites/usccb.siteym.com/resource/group/085a874d-f909-48df-8f95603bbf54c6c1/PAE_Refugee_Integration_Metr.pdf

Sunstein, C. R., Reisch, L. A., \& Rauber, J. (2018). A worldwide consensus on nudging? Not quite, but almost. Regulation and Governance, 12(1), 3-22.

Sunstein, C., \& Thaler, R. (2008). Nudge. The politics of libertarian paternalism. New Haven.

Sweller, J. (1988). Cognitive load during problem solving: Effects on learning. Cognitive Science, 12(2), 257-285.

Sweller, J., Van Merrienboer, J. J., \& Paas, F. G. (1998). Cognitive architecture and instructional design. Educational Psychology Review, 10(3), 251-296.

Tomm, B. M., \& Zhao, J. (2016). Scarcity captures attention and induces neglect: Eyetracking and behavioral evidence. In A. Papafragou, D. Grodner, D. Mirman, \& J. C. Trueswell (Eds.), Proceedings of the 38th annual conference of the Cognitive Science Society (pp. 1199-1204). Austin: Cognitive Science Society.

UNDP (2016). Behavioural Insights at the United Nations - Achieving Agenda 2030. United Nations Development Programme.

Link: http://www.undp.org/content/undp/en/home/librarypage/developmentimpact/behavioural-insights-at-the-united-nations--achieving-agenda-203.html

UNHCR (2016) Mid-year trends:

http://www.unhcr.org/statistics/unhcrstats/58aa8f247/mid-year-trends-june2016.html

Vallgårda, S. (2012). Nudge-A new and better way to improve health? Health Policy, 104(2), 200203.

Webb, T. L., \& Sheeran, P. (2006). Does changing behavioral intentions engender behavior change? A meta-analysis of the experimental evidence. Psychological Bulletin, 132(2), 249-268.

White, J. V. (2004). What is affirmative action? Scholarly Works. Paper 306.

World Bank. (2018). Behavioral Science around the World: Profiles of 10 Countries. World Bank. Working draft of Mind, Behavior and Development Unit. 
Link: http://documents.worldbank.org/curated/en/710771543609067500/Behavi oral-Science-Around-the-World-A-Profile-of-10-Countries-Working-Draft

World Health Organisation (2018) Migration and communicable diseases: no systematic association. Retrieved from: http://www.euro.who.int/en/healthtopics/health-determinants/migration-and-health/migrant-health-in-theeuropean-region/migration-and-health-key-issues\#292117 